Portland State University

PDXScholar

Engineering and Technology Management

Faculty Publications and Presentations

$9-1-2016$

\title{
A Framework for Technology Transfer Potential Assessment
}

Judith Estep

Portland State University

Tugrul U. Daim

Portland State University, tugrul@etm.pdx.edu

Follow this and additional works at: https://pdxscholar.library.pdx.edu/etm_fac

Part of the Operations Research, Systems Engineering and Industrial Engineering Commons Let us know how access to this document benefits you.

\section{Citation Details}

Estep, Judith and Daim, Tugrul U., "A Framework for Technology Transfer Potential Assessment" (2016). Engineering and Technology Management Faculty Publications and Presentations. 105.

https://pdxscholar.library.pdx.edu/etm_fac/105

This Article is brought to you for free and open access. It has been accepted for inclusion in Engineering and Technology Management Faculty Publications and Presentations by an authorized administrator of PDXScholar. Please contact us if we can make this document more accessible: pdxscholar@pdx.edu. 


\title{
A Framework for Technology Transfer Potential Assessment
}

\author{
Judith Estep ${ }^{1}$, Tugrul Daim ${ }^{2}$ \\ ${ }^{1}$ Bonneville Power Administration, Portland, Oregon - USA \\ ${ }^{2}$ Dept. of Engineering and Technology Management, Portland State University, Portland, OR - USA
}

\begin{abstract}
This paper is motivated by a need to move research into application, specifically in the utility industry. There are many challenges facing the industry: an aging infrastructure, a growing population, and aggressive energy efficiency targets are just a few examples. Many technologies exist or are in development but the rate at which they are being adopted is slow. Despite a clear need to apply research results to the utility industry, a cursory review of how research proposals are evaluated within the utility industry confirms that technology transfer is only peripherally addressed. In addition, there is no mechanism to quantitatively assess the technology transfer potential of a research proposal. The goal of this paper is to develop an assessment model that can be used to identify the technology transfer potential of a research proposal. By doing so, an organization can select the proposals whose research outcomes are more likely to move into application.
\end{abstract}

\section{INTRODUCTION}

While there are voluminous amounts of information about technology transfer and attributes of successful technology transfer, there is a lack of information about how technology transfer is done, specifically in the utility industry. In other words, what success attributes are important to facilitate technology transfer (TT)? These statements are supported when reviewing the evaluation criteria of organizations that fund technology proposals.

The paper is motivated by the significant changes in the utility industry and the need to transfer technology to solve pertinent problems. The 2009 Recovery Act has enabled a significant investment in energy related $R \& D$ - to date in excess of $\$ 11 \mathrm{~B}$ has been spent on energy related technologies, specifically demand response and energy efficiency. While the bulk of these investments have been focused on renewable integration, the resulting research would have an impact on the entire transmission system. There are important considerations about system stability, data availability and integrity, and system reliability as a result of the need to integrate renewable energy. Yet, despite substantial investments and the subsequent availability of technologies, researchers suggest that there will be a lag in implementing these technologies.

\section{BACKGROUND}

One assumed outcome of research is that it will be applied to solve a problem. In other words that the technology will be applied to address the problem. When should the technology transfer activities start? Literature suggests that technology transfer should not start once the research is finished. Rather, it is an integral part of the research and development process. The following literature review infers that TT should be considered as part of the research proposal evaluation process. Prior literature has been reviewed in prior recent publications $[1,2]$

In Mead and Presley's research [3] they connect the need to innovate and stay competitive to research that addresses an organization's strategic objectives. As such, they developed a model to select a research portfolio. The evaluation criteria include elements that consider the end-state of the research, in other words, the technology transfer. For example, the probability of market success, market size, existence of a project champion, and availability and competence of resources were assessed [3]. While technology transfer was not explicitly mentioned, consideration is given to the potential of project success and application or technology transfer.

Hsu, et al [4], explicitly mention technology transfer as part of their research project selection model. Their selection criteria considers the "...success rate of commercialization...the probability of the success in technology transfer, product development, and commercialization...". The authors also state that their methodology will help to develop better projects and hence improve the likelihood of commercialization and technology transfer.

Technology transfer is not a new concept. The considerable amount of literature agrees that defining technology transfer is difficult due to the complexity of the technology transfer process. The definitions vary depending on the organization, technology type, and technology maturity, among other factors.

The term technology transfer can be defined as the process of movement of technology from one entity to another. The transfer may be said to be successful if the receiving entity, the transferee, can effectively utilize the technology transferred and eventually assimilate it. The movement may involve physical assets, know-how, and technical knowledge. Technology transfer in some situations may be confined to relocating and exchanging of personnel or the movement of a specific set of capabilities. [5]

Technology transfer has also been used to refer to movements of technology from the laboratory to industry, developed to developing countries, or from one application to another domain [5].

The National Technology Transfer Center (NTTC) focuses on the players involved in federal technology transfer "...the purpose of a federal technology transfer program is to make federally generated scientific and technological developments accessible to private industry and state and 
local governments." The expectation is that the technology will be further developed once transferred and "...enhance our nation's industrial competitiveness or otherwise improve our quality of life." [6] A similar definition of federal research and technology transfer includes the reference to the serving public and private needs, "...technology transfer is the process by which existing knowledge, facilities or capabilities developed under federal research and development funding are utilized to fulfill public and private needs". [7] Further supporting the theme of providing efficiencies, the Transportation Research Board defines technology transfer as doing things better, “...technology transfer is the process by which research and other new technologies are transferred into useful process, products, and programs. Another way of saying the same thing is: technology transfer is the process by which a better way of doing something is put into use as quickly as possible." [8] At a very basic level technology transfer has been defined as simply, "...technology transfer addresses the assessment, adoption and implementation of technology" [7]

The definitions of technology transfer are as disparate as the organizations that apply them. Technology transfer includes knowledge transfer, enabling people or countries to be ready to accept new technologies - preparations, and involves many stakeholders to include national labs, government agencies, private industries, technical and management level personnel, as well as developing countries. As a result of the literature review it can be inferred that the definition of technology transfer is dependent on the context and the technology.

Frank Geels describes the multi-criteria aspects of technology transfer process, relative to sustainability transitions. In general, he emphasizes that, “...technological transitions no only involve the technology...but also changes in elements such as user practices, regulation, industrial networks, infrastructure...." [10] and "...technical trajectories are not only influenced by engineers, but also by users, policy makers, societal groups, suppliers, ..." [11] In this context, Geels refers to the technology transfer process as a relationship and describes the interaction of different perspectives as the "...dynamics of structural change...". [10] Geels identifies the unique levels of interaction: landscape developments, socio-technical regimes, and technological niches. Technology transitions occur when there is an interaction between the different levels. The interaction results from a need in the landscape created by the sociotechnical regime in the form of understanding user preferences, policy drivers, culture, etc. In anticipation, the niche has technology developments ready to respond to the landscape need - a window of opportunity is opened and the technology is transitioned. In other words, transition occurs when all three levels are synchronized and reinforce each other. A definition of each level is provided:

- Socio-technical landscape: impacted by external inputs; change happens slowly, typically over a period of decades. Relative to this research, the technology recipient can be seen as the landscape.

- Socio-technical regime: Influences the landscape through identification of market/user preferences, culture, and policy implementation

- Niche - Innovations: research and development of new technologies occurs in this space.

A verbatim explanation from Frank Geels puts context around the relationship: [12] “...(a) niche-innovations build up internal momentum, through learning processes, price/performance improvements, and support from powerful groups, (b) changes at the landscape level create pressure on the regime and (c) destabilization of the regime creates a window of opportunity for niche-innovations. The alignment of these processes enables the breakthrough of these...technologies...". The different levels are similarly described in several of Geels' research [10, 11, 12, 13, 14].

Geels' explains issues with sustainable technology transitions. These include not offering obvious benefits for the end-user, comfort level with incumbent technologies which requires a strategic over-haul of those who support existing technologies, existing infrastructures, and user practices that are aligned with the existing technology. [10] In this proposal, a utility is seen as the incumbent.

Sharma's dissertation [16] describes the technology transfer process through time and also clearly shows building a relationship as a prominent theme to successful technology transfer:

The relationship theme is also prominent in the work of Franza, R.M., and K.P. Grant. "Improving Federal to Private Sector Technology Transfer," Research-Technology Management 49, no. 3 (2006): 36-40 [17]. The attributes they identify as necessary for technology transfer demonstrate that a relationship is important. Franza and Grant highlight the "difference makers" - those attributes which are essential for successful technology transfer.

For the purposes of this research the relationship definition of technology transfer will be understood as transfer of a technology or application from a research partner (e.g. national lab, industry partner, university, or an internal researcher) to a utility. Analogous to Geels research, the research partner can be seen as developing the niche innovations and the research drivers (renewable integration, meeting energy efficiency targets, etc.) and utilities are represented by the socio-technical landscape. The objective is for these technologies to help a utility address the challenges of an aging infrastructure, meeting energy efficiency targets, integrating renewable resources, or accommodating load growth.

\section{METHODOLOGY}

This research uses an analytical approach to develop a decision model that calculates a technology transfer score for assessing research proposals. Experts are invited to provide 
judgmental data to determine the relative relationships among the decision elements at various levels of the model. The initial part of the research includes one on one meetings with the experts to identify critical issues and define the criteria. Following pair-wise comparison instruments are developed based on the results provided by the experts in the interviews. The hierarchical decision model (HDM) method is used to quantify experts' judgmental data on the issues. The HDM provides a systematic approach to determine priorities for alternatives based on the experts' judgments. A hierarchy structure is constructed to represent a decision problem. HDM utilizes pair-wise comparisons to determine priorities for the alternatives or criteria based on the experts' opinions. The appropriate alternatives are decided based on the quantitative solution to these rankings. HDM is used because of its many benefits: 1) HDM allows for the measurement of both objective and subjective factors; 2) Consistency measures are easily derived to evaluate the quality of the judgment; and 3) HDM enables group judgment to arrive at a unique decision that can represent the opinions of all participants. [9]

\section{MODEL BUILDING}

Assuming the ultimate goal of research is to apply results, it is important to understand how the transfer occurs most effectively. The objective of this research is to develop a decision model that calculates a technology transfer score for assessing research proposals.

Initially the research was organized using Linstone's technical, organizational, and personnel perspectives, with success attributes assigned to each perspective. When the structure was considered further using a preliminary content validation, it was apparent that different perspectives were required to describe the interaction necessary for successful technology transfer. The revised perspectives, a definition, and corresponding literature citations are provided.

\section{A. Organizational Strategies:}

This perspective refers to the strategies developed between the research organization and the technology recipient. Strategies consider how similar the research partners are, in terms of organizational structure, their location, and how many stakeholders are involved in the technology transfer transaction. For the purposes of this proposal the research organizations include 5 likely partners: Universities, Collaborative Partnerships (EPRI, CEATI, etc.), National Labs (LBNL, PNNL, etc.), Industry Partners (Intel, IBM, etc.), and other utilities (So Cal Edison, Consolidated Edison, etc.); the general research consensus is that a "transfer culture" is necessary for effective TT [17].

A summary of the organizational strategies that have been identified as necessary for successful technology transfer are characterized in table 1.

\section{B. Technology Elements:}

This perspective considers actions related to the technology as important for successful technology transfer. Actions include the researcher's previous cooperative experience and ability to demonstrate the technology, understanding of the recipient's technology needs, and the existence of and ability of the Technology Transfer Office to be effective at marketing the technology.

A summary of success attributes grouped under the perspective of technology elements is provided in Table 2.

TABLE 1: ORGANIZATIONAL STRATEGIES

\begin{tabular}{|c|c|c|}
\hline Perspective & Success Attributes & Attribute Descriptors \\
\hline \multirow[t]{6}{*}{$\begin{array}{l}\text { Organizational } \\
\text { Strategies }\end{array}$} & Organizational Homogeneity & $\begin{array}{ll}\text { - } & \text { Strategic alignment } \\
\text { - } & \text { High degree of institutionalization } \\
& \text { Similar industries and composition of } \\
\text { - } & \text { Similar size of firms } \\
\text { - } & \text { Similar motivations for doing research } \\
\text { - } \quad \text { Similar expectations for success } \\
(17,20,21,22,25,26,29)\end{array}$ \\
\hline & Bureaucracy & - Level of detail in contracts $(22,23,26)$ \\
\hline & Budget flexibility & - $\quad$ Budget flexibility $(17,20,21,22)$ \\
\hline & Geographic proximity & $\begin{array}{l}\text { - Geographic proximity facilitates TT }(17,22 \text {, } \\
29,31,32)\end{array}$ \\
\hline & Propensity for Risk & - $\quad$ Propensity for risk (24) \\
\hline & Technical Complexity & $\begin{array}{l}\text { High complexity: Multiple stakeholders, } \\
\text { across regions Low complexity: single users, } \\
\text { isolated to a business line }(25,28,29)\end{array}$ \\
\hline
\end{tabular}




\section{Proceedings of PICMET '16: Technology Management for Social Innovation}

TABLE 2: TECHNOLOGY ELEMENTS

\begin{tabular}{|c|c|c|}
\hline Perspective & Success Attributes & Attribute Descriptors \\
\hline \multirow{5}{*}{$\begin{array}{l}\text { Technology } \\
\text { Elements }\end{array}$} & Cooperative Experience & - Previous cooperative experience $(25,31)$ \\
\hline & Understanding the recipient & - Understand perceptions of adopters $(16,21,35)$ \\
\hline & Educate/Demonstrate Technology & - Educate/Demonstrate technology $(21,25,29,33)$ \\
\hline & Dedicated TTO & - Dedicated TTOs (17) \\
\hline & TTO Staffed with Marketing Experience & - Staffed with marketing experience (34) \\
\hline
\end{tabular}

\section{Social Strategies:}

The emphasis on social strategies is how to develop and maintain a relationship between the researchers and recipients such that technology transfer is more likely to occur. This perspective and associated success attributes identify the necessary activities to facilitate a successful technology transfer. The general consensus among the research was that a "transfer culture" is necessary for effective technology transfer [49].

Social strategy attributes that literature identified as necessary for successful technology transfer are include in Table 3.

\section{Market Readiness:}

This perspective assesses the market's readiness to accept the new technology - has a market-pull be sufficiently created such that it (the market) has a need established and assessed for the technology? The success attributes that support this perspective include: a business plan has been created, financial feasibility has been confirmed, common standards exist, there is an appropriate level of support from management, and government incentives exist to make the technology more appealing to use or be adopted on a larger scale. Table 4 summarizes the technology transfer success attributes that are characterized under the market readiness perspective.

TABLE 3: SOCIAL STRATEGIES

\begin{tabular}{|l|l|l|}
\hline \multicolumn{1}{|c|}{ Perspective } & \multicolumn{1}{|c|}{ Success Attributes } & \multicolumn{1}{c|}{ Attribute Descriptors } \\
\hline \multirow{2}{*}{ Social Strategies } & $\begin{array}{l}\text { Creating an Atmosphere of } \\
\text { Trust }\end{array}$ & - Strong and frequent communication $(17,25,29,30,31,32)$ \\
\hline & Cultural Awareness & - Cultural awareness $(25,29,31,32)$ \\
\hline Personnel Involved in TT & - TT recipients involved in the R\&D phase / Inventors involved in TT (20,36) \\
\hline Manpower Flexibility & - Manpower flexibility; favorable leave policies $(21,24)$ \\
\hline Rewards System in Place & - Rewards system in place $(17,25,29,30,31)$ \\
\hline
\end{tabular}

TABLE 4: MARKET READINESS

\begin{tabular}{|c|c|c|}
\hline Perspective & Success Attributes & Attribute Descriptors \\
\hline \multirow[t]{6}{*}{ Market Readiness } & Business Plan Exists & $\begin{array}{l}\text { - Clearly defined need is created }(17,21) \\
\text { - Recipient domain has business plan for commercialization; Diffusion } \\
\text { process needs to be induced }(17,21)\end{array}$ \\
\hline & Government Incentives & - Technology incentives available for recipient (21) \\
\hline & Financial Feasibility & - Financial feasibility assessed (16) \\
\hline & $\begin{array}{l}\text { Organizational Champion for } \\
\text { Technology }\end{array}$ & - Strong organizational champion for the technology $(21,22$ 37) \\
\hline & $\begin{array}{l}\text { Technology Transfer Initiated } \\
\text { by Top Management }\end{array}$ & - Technology transfer initiated by top management (22) \\
\hline & $\begin{array}{l}\text { Common standards and codes } \\
\text { exist and are supported }\end{array}$ & $\begin{array}{l}\text { - Favorable regulatory factors; governments can and did influence the choice } \\
\text { of a single standard (by either a large single country or region) dramatically } \\
\text { and instantaneously increased the forecast for the technology, thus causing } \\
\text { other countries to also adopt the standard. }(9,21)\end{array}$ \\
\hline
\end{tabular}


These perspectives are the basis for presenting a conceptual framework for the interactive, complex relationship that is necessary for successful technology transfer. The relationship includes organizational strategies which describe characteristics of the actors involved in technology transfer; technology transfer actors are described in the success attribute taxonomy in section 6.2. Technology elements are related to the attributes of the technology being transferred, while social strategies consider attributes related to the personnel policies and actions. Finally, market readiness includes those attributes that prepare and facilitate the technology recipient organizations. This framework and subsequent technology transfer score will help an organization close the gap between technologies just being available to their actual adoption and delivery of expected results.

Much the same way Geels and Sharma describe an interaction between levels to capture the technology transfer relationship, the proposed conceptual model describes a similar relationship. However, this research goes a step further to specify the success attributes associated with technology transfer, using a multi-perspective view. In total the literature review identified 59 success attributes, across the four perspectives, which contribute to successful technology transfer; in some cases the success attributes were grouped based on similar concepts, resulting in 22 as shown in Figure 1.

\section{RESULTS}

Table 5 shows the final model developed through the expert interviews. The weight for perspectives and attributes were calculated through pairwise comparisons by the experts.

The results indicate that Market Readiness is the most important factor when it comes to technology transfer.

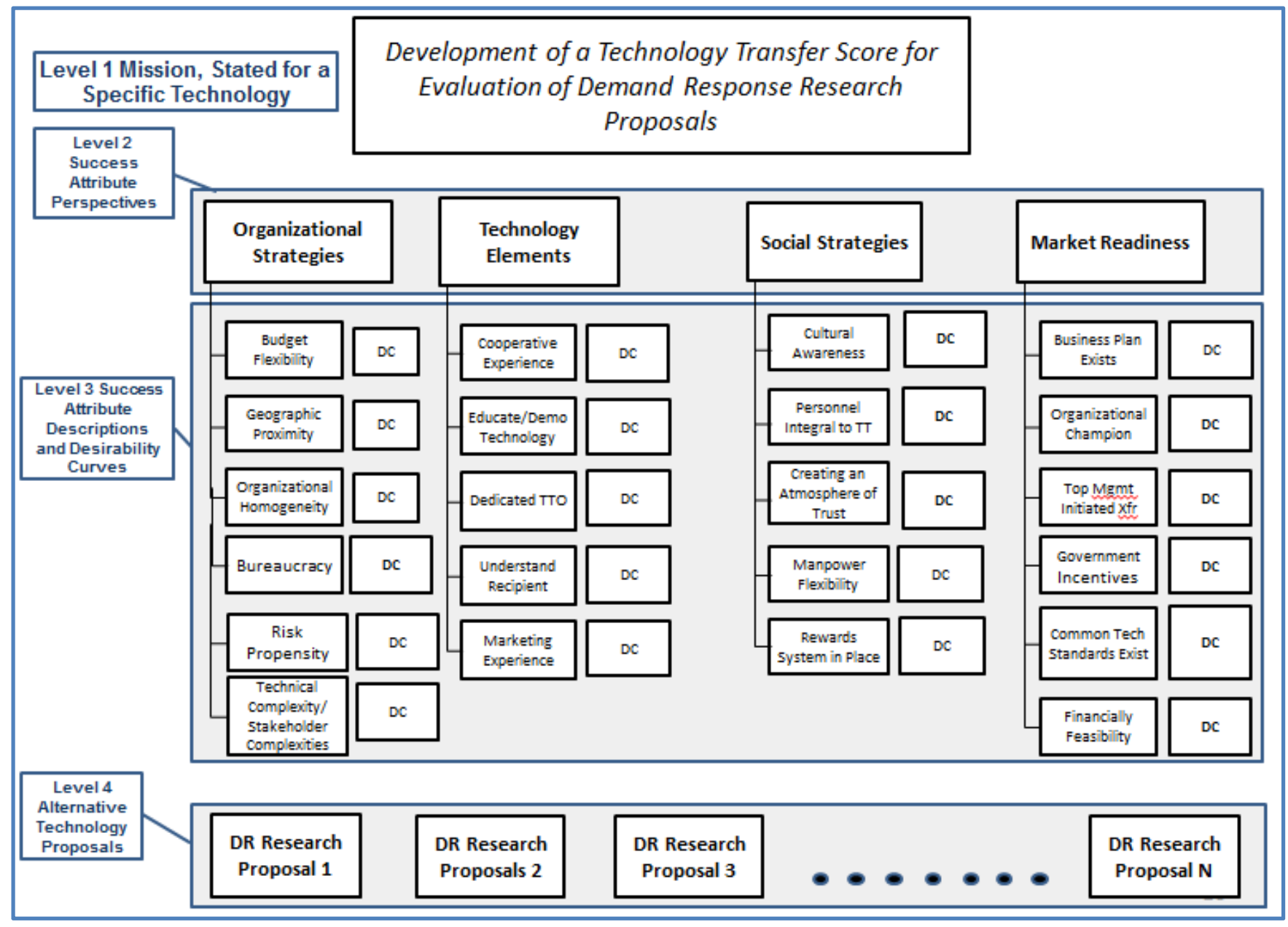

Figure 1: Proposed Technology Transfer Score Model 


\begin{tabular}{|c|c|c|c|c|}
\hline \multirow[b]{2}{*}{ Perspectives } & \multirow[b]{2}{*}{ Value } & \multicolumn{2}{|c|}{ Success Attributes } & \multirow{2}{*}{$\begin{array}{c}\text { Success Attribute } \\
\text { Global Value - } \\
\text { Contribution to TT } \\
\text { Score } \\
\end{array}$} \\
\hline & & Attribute & Local Value & \\
\hline \multirow{5}{*}{$\begin{array}{l}\text { Organizational } \\
\text { Strategies }\end{array}$} & \multirow{5}{*}{0.18} & Budget Flexibility & 0.18 & 0.032 \\
\hline & & Geographic Proximity & 0.14 & 0.025 \\
\hline & & Bureaucracy & 0.17 & 0.031 \\
\hline & & Risk Propensity & 0.27 & 0.049 \\
\hline & & Technical \& Stakeholder Complexity & 0.25 & 0.045 \\
\hline \multirow{5}{*}{ Social Strategies } & \multirow{5}{*}{0.20} & Cultural Awareness & 0.12 & 0.024 \\
\hline & & Personnel Integral to TT & 0.27 & 0.054 \\
\hline & & Create an Atmosphere of Trust & 0.28 & 0.056 \\
\hline & & Manpower Flexibility & 0.16 & 0.032 \\
\hline & & Rewards System in Place & 0.16 & 0.032 \\
\hline \multirow{5}{*}{$\begin{array}{l}\text { Technology } \\
\text { Elements }\end{array}$} & \multirow{5}{*}{0.23} & Cooperative Experience & 0.18 & 0.041 \\
\hline & & $\begin{array}{l}\text { Education/Demonstration About the } \\
\text { Technology }\end{array}$ & 0.22 & 0.051 \\
\hline & & Dedicated TTO & 0.17 & 0.039 \\
\hline & & Understanding the Recipient & 0.32 & 0.074 \\
\hline & & Marketing Experience & 0.10 & 0.023 \\
\hline \multirow{6}{*}{ Market Readiness } & \multirow{6}{*}{0.39} & Business Plan Exists & 0.19 & 0.074 \\
\hline & & Organizational Champion & 0.16 & 0.062 \\
\hline & & Top Management Initiated TT & 0.21 & 0.082 \\
\hline & & Government Incentives Exist & 0.09 & 0.035 \\
\hline & & Common Technology Standards & 0.15 & 0.059 \\
\hline & & Financial Feasibility & 0.20 & 0.078 \\
\hline Total & 1.0 & & & 1.0 \\
\hline
\end{tabular}

\section{CONCLUSIONS}

This paper described a hierarchical decision model to assess research proposals for their potential of technology transfer. As identified in literature and reinforced with practical examples, this model fills a gap of quantitatively assessing technology transfer potential during the research and development phase. The model identifies and quantifies the relative value of technology transfer success attributes and provides a tool that can be used during the research proposal selection process. This tool would be used a supplement to other evaluation criteria.

\section{REFERENCES}

[1] Estep J "Development of a Technology Transfer Score to Inform the Selection of a Research Proposal" PICMET Proceedings, 2015

[2] Estep J, Daim T, Multiple Perspectives of Technology Transfer: Technology Transfer from Government Labs PICMET Proceedings, 2013

[3] Meade, L. and Presley, A., "R\&D Project Selection Using the Analytic Network Process", IEEE Transactions on Engineering Management, Vol 49, No. 1, February 2002

[4] Hsu, Y., Gwo-Hshing,T., and Shyu, J., "Fuzzy Multiple Criteria Selection of Government-Sponsored Frontier Technology R\&D projects", R\&D Management, Vol 33, 5, 2003

[5] K. Ramanathan. "An Overview of Technology Transfer and Technology Transfer Models". Available Online: http://www.businessasia.net/Pdf_Pages/Guidebook\%20on\%20Technol ogy\%20Transfer\%20Mechanisms/An\%20overview\%20of\%20TT\%20an d\%20TT\%20Models.pdf

[6] National Technology Transfer Center (NTTC), USA http://www.nttc.edu/products/guide/seca01.html

[7] Lecture: Daim, T., "Technology Transfer (Research Phase)", ETM 533, Summer 2011, Portland State University, Portland, OR
[8] "What is Technology Transfer?" Available Online: http://onlinepubs.trb.org/onlinepubs/millennium/00114.pdf

[9] Neshati, Ramin, "Participation in Technology Standards Development: A Decision Model for the Information and Communications Technology Industry" (2014). Dissertations and Theses. Paper 1850.

[10] Geels, Frank, "The Multi-Level Perspective on Sustainability Transitions: Responses to Seven Criticisms", Environmental Innovation and Societal Transitions, 1(2011) 24-40

[11] Geels, Frank, "Technological Transitions as Evolutionary Reconfiguration Processes: A Multi-Level Perspective and a CaseStudy", Research Policy, 31 (2002) 1257-1274

[12] Geels, Frank and Schot, Johan, "Typology of Sociotechnical Transition Pathways", Research Policy, 36 (2007) 399-417

[13] Verbong, GPJ and Geels, Frank, "Exploring Sustainability Transitions in the Electricity Sector with Socio-Technical Pathways", Technological Forecasting and Social Change, 77 (2010) 1214-1221

[14] Verbong, GPJ and Geels, Frank, "The Ongoing Energy Transition: Lessons from a Socio-Technical, Multi-Level Analysis of the Dutch Electricity System (1960 - 2004)”, Energy Policy, 35 (2007) 1025 1037

[15] Meseri, O and Maital, S, "A Survey Analysis of University-Technology Transfer in Israel: Evolution of Projects and Determinants for Success", Journal of Technology Transfer, 26, (2001) 115-126

[16] Sharma, Kishandutt Jaydayal "A new inquiring system for technology transfer and its role in planning and policymaking", (1973). Dissertations and Theses. Paper 582.

[17] Franza, R.M., and K.P. Grant. "Improving Federal to Private Sector Technology Transfer," Research-Technology Management 49, no. 3 (2006): 36-40

[18] DOE TRL definitions Available: http://en.wikipedia.org/wiki/Technology readiness level

[19] NASA TRL Heat Map Available: http://www.nasa.gov/directorates/heo/scan/engineering/technology/txt accordion 1 prt.htm

[20]Ham, R.M., and D.C. Mowery. "Improving Industry-government Cooperative R\&D” Issues in Science and Technology 11, no. 4 (1995): $67-73$ 


\section{Proceedings of PICMET '16: Technology Management for Social Innovation}

[21]P. Balachandra, H. S. Kristle Nathan, and B. S. Reddy, "Commercialization of sustainable energy technologies," Renewable Energy, vol. 35, no. 8, pp. 1842-1851, 2010

[22]B. Bozeman, "Technology transfer and public policy: a review of research and theory," Research policy, vol. 29, no. 4-5, pp. 627-656, 2000

[23]Franza, R.M., K.P. Grant, and W.A. Spivey. "Technology Transfer Contracts Between R\&D Labs and Commercial Partners: Choose Your Words Wisely." The Journal of Technology Transfer (n.d.): 1-11

[24] Perry IV, T.D. Ampulse Corporation: A Case Study on Technology Transfer in US Department of Energy Laboratories. National Renewable Energy Laboratory (NREL), Golden, CO., 2010

[25] WEN-HSIANG, LAI, and C.T.Z.U. TSAI. "Analyzing Influence Factors of Technology Transfer Using Fuzzy Set Theory" PICMET Proceedings, 2008

[26] L. Lutzenhiser, "Innovation and organizational networks Barriers to energy efficiency in the US housing industry," Energy Policy, vol. 22, no. 10 , pp. 867-876, 1994

[27] O'Malley, Mark, Meeting Topic: Pacific Northwest Renewable Integration, BPA, Sept 17, 2012

[28] M. Mueller and R. Wallace, "Enabling science and technology for marine Renewable energy," Energy Policy, vol. 36, no. 12, pp. 43764382, 2008

[29] Greiner, M.A., and R.M. Franza. "Barriers and Bridges for Successful Environmental Technology Transfer" The Journal of Technology Transfer 28, no. 2 (2003): 167-177

[30] Rogers, Everett M., Shiro Takegami, and Jing Yin. "Lessons Learned About Technology Transfer." Technovation 21, no. 4 (April 2001): $253-261$
[31] E. M. Mora-Valentin, A. Montoro-Sanchez, and L. A. Guerras-Martin, "Determining factors in the success of R\&D cooperative agreements between firms and research organizations," Research Policy, vol. 33, no. 1, pp. 17-40, 2004

[32] Boulter, L., and T. Bendell, "Managing the Technology Transfer Process" In Engineering Management Conference, 2002, IEMC'02. 2002 IEEE International, 2:643-648, 2002

[33] Spann, M.S., M. Adams, and W.E. Souder. "Measures of Technology Transfer Effectiveness: Key Dimensions and Differences in Their Use by Sponsors, Developers and Adopters." Engineering Management, IEEE Transactions vol 42, no. 1 (1995): 19-29

[34] Siegel, D.S., D.A. Waldman, L.E. Atwater, and A.N. Link. "Toward a Model of the Effective Transfer of Scientific Knowledge from Academicians to Practitioners: Qualitative Evidence from the Commercialization of University Technologies." Journal of Engineering and Technology Management 21, no. 1-2 (2004): 115-142

[35] Isaacs, E.A., J.C. Tang, J. Foley, J. Johnson, A. Kuchinsky, J. Scholtz, and J. Bennett. "Technology Transfer: So Much Research, so Few Good Products." In Conference Companion on Human Factors in Computing Systems: Common Ground, 155-156, 1996

[36] Rogers, E.M., E.G. Carayannis, K. Kurihara, and M.M. Allbritton. "Cooperative Research and Development Agreements (CRADAs) as Technology Transfer Mechanisms," R\&D Management 28, no. 2 (1998): 79-88

[37] J. P. Painuly, "Barriers to renewable energy penetration; a framework for analysis," Renewable Energy, vol. 24, no. 1, pp. 73-89, 2001 